\title{
Interaction between physical activity and problematic mobile phone use on suicidality in Chinese college students
}

Yang Xie ${ }^{1 \dagger}$, Ming Zhu ${ }^{2 \dagger}$, Xiaoyan $\mathrm{Wu}^{1,3,4,5}$, Shuman Tao ${ }^{6}$, Yajuan Yang ${ }^{7}$, Tingting $\mathrm{Li}^{1}$, Liwei Zou ${ }^{1}$, Honglv Xu ${ }^{1}$ and Fangbiao Tao ${ }^{1,3,4,5^{*}}$ (D)

\begin{abstract}
Background: Previous research has found a relationship between problematic mobile phone use (PMPU) and suicidality. However, few studies have examined the interaction effects between low physical activity (PA) and PMPU on suicidality among college students. This study aimed to examine the interactions of PA and PMPU and their impact on suicidality in a school-based sample among Chinese college students.

Methods: Analysis is based on date from two university in China, which recruited 4787 participants. Binomial logistic regression models were used to explore the associations of PA, PMPU with suicidal ideation and suicide attempt, as well as the interaction of PA and PMPU with suicidality.

Results: The prevalence of suicide attempt and suicidal ideation were 3.5 and $7.2 \%$, respectively. Low PA was significantly associated with suicide attempt $(\mathrm{OR}=3.48,95 \% \mathrm{Cl}: 2.52-4.81)$ and suicidal ideation $(\mathrm{OR}=1.90,95 \% \mathrm{Cl}$ : 1.46-2.46). PMPU was significantly associated with suicide attempt $(\mathrm{OR}=3.65,95 \% \mathrm{Cl}: 2.66-5.01)$ and suicidal ideation ( $\mathrm{OR}=2.83,95 \% \mathrm{Cl}$ : 2.25-3.54). Interaction analysis indicated that low PA and PMPU were interactively associated with suicide attempt $(\mathrm{OR}=9.51,95 \% \mathrm{Cl}$ : 6.15-14.73, $P<0.001)$, RERI $=4.85(1.20-8.50)$, AP $=0.51(0.29-0.73)$, $\mathrm{SI}=2.32(1.34-4.04)$. There was no additive interaction effects between PA and PMPU on suicidal ideation.

Conclusions: The findings reveals that the intervention programs of suicide attempt should consider the students PA levels and PMPU.
\end{abstract}

Keywords: Physical activity, Problematic mobile phone use, Suicidality, College students, Interaction

\section{Background}

College students are in a critical period of life, facing various of challenges and risks during the transition from school to society. Research shows that mental health issues are common among college students [1].

\footnotetext{
* Correspondence: taofangbiao@126.com

${ }^{\dagger}$ Yang Xie and Ming Zhu contributed equally to this work and should be considered co-first authors.

'Department of Maternal, Child and Adolescent Health, School of Public Health, Anhui Medical University, No 81 Meishan Road, Hefei 230032, Anhui, China

${ }^{3}$ MOE Key Laboratory of Population Health Across Life Cycle, No 81 Meishan Road, Hefei 230032, Anhui, China

Full list of author information is available at the end of the article
}

Suicide is the second leading cause of death among adolescents worldwide [2, 3]. A meta-analysis suggested relatively high proportions of college students have suicidal thoughts and behaviors in the past 12 months [4]. Multiple studies have shown that the incidence of 12month suicide ideation in college students estimates in the 5\% 35\% range, and 12-month suicide attempts range from 0.6 to $11 \%$ [5-9]. Furthermore, a metaanalysis based on Chinese college students reported that the overall pooled prevalence of suicidal ideation was $10.72 \%$ [10]. The reporting rate of Suicide attempt among college students in Chinese Chongqing was $1.7 \%$

(c) The Author(s). 2020 Open Access This article is licensed under a Creative Commons Attribution 4.0 International License, which permits use, sharing, adaptation, distribution and reproduction in any medium or format, as long as you give appropriate credit to the original author(s) and the source, provide a link to the Creative Commons licence, and indicate if changes were made. The images or other third party material in this article are included in the article's Creative Commons licence, unless indicated otherwise in a credit line to the material. If material is not included in the article's Creative Commons licence and your intended use is not permitted by statutory regulation or exceeds the permitted use, you will need to obtain permission directly from the copyright holder. To view a copy of this licence, visit http://creativecommons.org/licenses/by/4.0/. The Creative Commons Public Domain Dedication waiver (http://creativecommons.org/publicdomain/zero/1.0/) applies to the data made available in this article, unless otherwise stated in a credit line to the data. 
[11]. In general, Suicidal ideation and suicide attempt are major public health problems in college students [12].

In modern society, low physical activity have been found to increase with age in adolescence [13]. Meanwhile, with the progress of economy, mobile phone becomes an essential part of life. Despite its advantages of convenience and practicability, proper use of mobile phones has become critically important that cannot be ignored. Multiple studies have shown that the rate of PMPU in adolescents is 6.3-26\% [14-18]. Thus far, the interaction effects between PA and PMPU on college students' mental health has been concerned [19]. A substantial body of research has demonstrated significant independent effects between low physical activity (LPA) and problematic mobile phone use (PMPU) on suicidality $[6,20,21]$. Yet current knowledge surrounding the relationship of PA and PMPU with suicidality is predominantly derived from Western countries $[6,20,21]$.

However, there is also little research on the interaction effects between PA and PMPU on suicidal ideation and suicide attempt in college students, despite PA and PMPU being highly correlated. Therefore, the present research first sought to analyze the independent effects of PA and PMPU on suicidal ideation and suicide attempt in Chinese college students, and then sought to explore the additive interaction effects between PA and PMPU on suicidal ideation and suicide attempt.

\section{Methods}

\section{Participants}

The participants were recruited from a medical university and a comprehensive normal university located in Hefei, Anhui Province, and Shangrao City, Jiangxi Province, by using stratified cluster sampling. Firstly, two cities were selected by convenient sampling. Then, two schools were based on the stratified cluster sampling. Lastly, professional and class were selected randomly from medical university and comprehensive normal university. Data for this study were collected from June to July 2018. A total of 4787 college students were recruited as research objects for questionnaire surveys to assess the behaviors and mental health. Teachers and professional investigators described the questionnaires to the students and distributed them a quick response (QR) code for scanning using their cell phones in the classroom, thus allowing them to complete the electronic questionnaires. Excluding the incomplete questionnaires, there were 4624 valid questionnaires. The response rate was $96.6 \%$. The design and data collection were reviewed and approved by the Ethics Committee of Anhui Medical University. All participants wrote informed consent for inclusion prior to the administration of the survey.

\section{Measures}

\section{Sociodemographic data}

Sociodemographic data for participants were collected by questionnaire, including age, gender (male or female), grade (freshman, sophomore or junior student), registered residential background (rural or urban), only child, parents' education level (less than high school degree or more) and self-reported family economy (bad, general or good).

\section{Physical activity}

The International Physical Activity Questionnaire Short Version (IPAQ-SF) was used to measure PA [22, 23]. IPAQ-SF comprised 8 items, which evaluates the frequency and duration of PA in the past week among college students. In this study, PA level was divided into low physical activity (LPA $=3.3$ metabolicequivalent $[\mathrm{METs}]$ ), moderate physical activity (MPA = 4.0 METs) and above. The criteria for low physical activity level are no physical activity reported or energy expenditure not enough to the MPA criteria. The moderate physical activity and above level is any combination of activities of three intensity ranges of at least $\mathrm{EE} \geq 600 \mathrm{MET} \mathrm{min} /$ week.

\section{Problematic Mobile phone use}

The Self-rating Questionnaire for Adolescent Problematic Mobile Phone Use (SQAPMPU) [24] was used to measure PMPU among college students. The questionnaire comprised of 13-items that included 3 dimensions named withdrawal symptoms, craving, and physical and mental health status. Each item responded to a 5-point Likert scale (not true at all, slightly true, moderately true, strongly true, extremely true). The total scores ranged from 13 to 65 , those who scores $\geq 29$ were defined as PMPU, using the 75th percentile as the cutoff point.

\section{Suicidal ideation and suicide attempt}

Suicidal ideation and suicide attempt were evaluated by the 2013 Youth Risk Behavior Surveillance System in the USA [25]. There were two questions on the questionnaire that assessed suicidal ideation, all the response options were "yes" or "no": "Have you seriously considered suicide in the last year?" and "Have you made any plans about how to commit suicide in the last year?" Meanwhile, the questions "How many suicide attempts have you actually made in the last year?" were adopted to evaluate suicide attempts, the response options were "never" or "once or more".

\section{Statistical analysis}

All statistical analyses were conducted using SPSS version 23.0(SPSS, Chicago, IL, USA) and an Excel spreadsheet set up by Tomas Anderson. We conducted chisquare test to compare the incidence of suicidal ideation and suicide attempt among different sociodemographic 
variables, PA and PMPU. Binomial logistic regression models were employed to examine the associations of PA, PMPU with suicidal ideation and suicide attempt and to evaluate the interaction of PA and PMPU with suicidality, adjusting for confounding factors. According to Table 1, not all confounding factors were significant for suicidality, thus we did not include all confounding factors in Tables 2 and 3. In this study, statistical significance was set at $P<0.05$.

\section{Results}

\section{Characteristics of participants}

Table 1 displayed the frequency characteristics and group differences of the college students in current study. There were responses from 4624 college students aged between 17 and 25 years old (mean \pm SD: $19.91 \pm$ 1.27 years), 2058 were males (44.5\%) and 2566 were females (55.5\%). We observed low physical activity in $16.4 \%$ and PMPU in $27.5 \%$ of participants. Overall, 164 (3.5\%) college students reported suicide attempt and 331 (7.2\%) college students reported suicidal ideation in the last year. However, there was no sex-based significance for suicide attempt $(P=0.20)$ and suicidal ideation $(P=$ $0.62)$. Suicide attempt and suicidal ideation revealed no statistically significant differences by registered residence and parents' education level. College students reporting only child and bad self-reported family economy showed higher rates of having suicide attempt and suicidal ideation. Junior students showed higher rates of having suicidal ideation. Furthermore, college students who were

Table 1 Frequency characteristics of suicidality in College Students (\%)

\begin{tabular}{|c|c|c|c|c|c|c|c|}
\hline \multirow[t]{2}{*}{ Variable } & \multirow[t]{2}{*}{$N=4624$} & \multicolumn{2}{|c|}{ Suicide attempt } & \multirow[t]{2}{*}{$x^{2}$ value } & \multicolumn{2}{|c|}{ Suicidal ideation } & \multirow[t]{2}{*}{$\mathrm{x}^{2}$ value } \\
\hline & & \multicolumn{2}{|c|}{$\operatorname{Yes}(n=164)$ No $(n=4460)$} & & \multicolumn{2}{|c|}{$\operatorname{Yes}(n=331)$ No $(n=4293)$} & \\
\hline Male & $2058(44.5)$ & $81(3.9)$ & 1977(96.1) & & $143(6.9)$ & $1915(93.1)$ & \\
\hline Female & $2566(55.5)$ & $83(3.2)$ & $2483(96.8)$ & & $188(7.3)$ & $2378(92.7)$ & \\
\hline Grade & & & & 3.60 & & & $8.20^{*}$ \\
\hline Freshman & 1617 (35.0) & $48(3.0)$ & $1569(97.0)$ & & $91(5.6)$ & $1526(94.4)$ & \\
\hline Sophomore & 1619 (35.0) & $57(3.5)$ & $1562(96.5)$ & & $128(7.9)$ & $1491(92.1)$ & \\
\hline Junior student & $1388(30.0)$ & $59(4.3)$ & $1329(95.7)$ & & $112(8.1)$ & $1276(91.9)$ & \\
\hline Registered residence & & & & 1.84 & & & 2.41 \\
\hline Rural & $2411(52.1)$ & $77(3.2)$ & $2334(96.8)$ & & $159(6.6)$ & $2252(93.4)$ & \\
\hline Urban & $2213(47.9)$ & $87(3.9)$ & $2126(96.1)$ & & $172(7.8)$ & $2041(92.2)$ & \\
\hline Only child & & & & $8.41^{*}$ & & & $17.38^{* *}$ \\
\hline Yes & $1441(31.2)$ & $68(4.7)$ & $1373(95.3)$ & & $137(9.5)$ & $1304(90.5)$ & \\
\hline No & $3183(68.8)$ & $96(3.0)$ & 3087 (97.0) & & $194(6.1)$ & 2989 (93.9) & \\
\hline Paternal education & & & & 1.98 & & & 0.05 \\
\hline$<12$ years & $2975(64.3)$ & $114(3.8)$ & $2861(96.2)$ & & $211(7.1)$ & $2764(92.9)$ & \\
\hline$\geq 12$ years & 1649 (35.7) & $50(3.0)$ & $1599(97.0)$ & & $120(7.3)$ & $1529(92.7)$ & \\
\hline Maternal education & & & & 0.31 & & & 2.23 \\
\hline$<12$ years & 3469 (75.0) & $120(3.5)$ & $3349(96.5)$ & & $237(6.8)$ & $3232(93.2)$ & \\
\hline$\geq 12$ years & $1155(25.0)$ & $44(3.8)$ & $1111(96.2)$ & & $94(8.1)$ & $1061(91.9)$ & \\
\hline Self-reported family economy & & & & $11.55^{*}$ & & & $34.35^{* *}$ \\
\hline Bad & $1434(31.0)$ & $70(4.9)$ & $1364(95.1)$ & & $139(9.7)$ & $1295(90.3)$ & \\
\hline General & $2903(62.8)$ & $83(2.9)$ & $2820(97.1)$ & & $159(5.5)$ & $2744(94.5)$ & \\
\hline Good & $287(6.2)$ & $11(3.8)$ & $276(96.2)$ & & $33(11.5)$ & $254(88.5)$ & \\
\hline PA & & & & $63.73^{* *}$ & & & $24.05^{* *}$ \\
\hline Low & $757(16.4)$ & $64(8.5)$ & $693(91.5)$ & & $86(11.4)$ & $671(88.6)$ & \\
\hline Moderate and above & 3867 (83.6) & $100(2.6)$ & 3767 (97.4) & & $245(6.3)$ & $3622(93.7)$ & \\
\hline PMPU & & & & $72.84^{* *}$ & & & $87.05^{* *}$ \\
\hline Yes & $1271(27.5)$ & $93(7.3)$ & 1178 (92.7) & & $164(12.9)$ & 1107 (87.1) & \\
\hline No & $33,537(72.5)$ & $71(2.1)$ & 3282 (97.9) & & $167(5.0)$ & 3186 (95.0) & \\
\hline
\end{tabular}


Table 2 Association of PA, PMPU and suicidality in College Students

\begin{tabular}{|c|c|c|c|c|}
\hline \multirow[t]{2}{*}{ Variables } & \multicolumn{2}{|l|}{ Suicide attempt } & \multicolumn{2}{|l|}{ Suicidal ideation } \\
\hline & $\begin{array}{l}\text { Crude OR } \\
(95 \% \mathrm{Cl}) \\
\end{array}$ & $\begin{array}{l}\text { Adjusted OR } \\
(95 \% \mathrm{Cl})\end{array}$ & $\begin{array}{l}\text { Crude OR } \\
(95 \% \mathrm{Cl}) \\
\end{array}$ & $\begin{array}{l}\text { Adjusted OR } \\
(95 \% \mathrm{Cl})\end{array}$ \\
\hline \multicolumn{5}{|l|}{ PA } \\
\hline Moderate and above & 1.00 & 1.00 & 1.00 & 1.00 \\
\hline Low & $3.48(2.52-4.81)^{* *}$ & $2.96(2.13-4.13)^{* *}$ & $1.90(1.46-2.46) * *$ & $1.63(1.25-2.13)^{* *}$ \\
\hline \multicolumn{5}{|l|}{ PMPU } \\
\hline No & 1.00 & 1.00 & 1.00 & 1.00 \\
\hline Yes & $3.65(2.66-5.01)^{* *}$ & $3.17(2.30-4.38)^{* *}$ & $2.83(2.25-3.54)^{* *}$ & $2.62(2.09-3.30)^{* *}$ \\
\hline
\end{tabular}

low PA reported higher rates of having suicide attempt than have PA (8.5\% VS $2.6 \%$, respectively, $\mathrm{P}<0.001)$ and higher rates of having suicidal ideation (11.4\% VS 6.3\%, respectively, $\mathrm{P}<0.001)$. Higher rates of suicide attempt and suicidal ideation were also observed in those with PMPU $(\mathrm{P}<0.001$, Table 1$)$.

\section{Associations of PA, PMPU and suicidality}

Results from binomial logistic regression analysis showed that both $\mathrm{PA}(\mathrm{OR}=3.48,95 \% \mathrm{CI}: 2.52-4.81)$ $(\mathrm{OR}=1.90,95 \% \mathrm{CI}: 1.46-2.46)$ and $\mathrm{PMPU}(\mathrm{OR}=3.65$, 95\%CI: 2.66-5.01) $(\mathrm{OR}=2.83,95 \% \mathrm{CI}: 2.25-3.54)$ are independently associated with suicide attempt and suicidal ideation ( $\mathrm{P}<0.001$ for each, Table 2). Adjusted models showed that PA $(\mathrm{OR}=2.96,95 \% \mathrm{CI}: 2.13-4.13)(\mathrm{OR}=$ 1.63, 95\%CI: $1.25-2.13)$ and PMPU $(\mathrm{OR}=3.17,95 \% \mathrm{CI}$ : 2.30-4.38) $(\mathrm{OR}=2.62,95 \% \mathrm{CI}: 2.09-3.30)$ was related to suicide attempt and suicidal ideation (Table 2).

\section{Interactions of PA, and PMPU with suicidality}

The results of a regression analysis examining the interactions of PA and PMPU with suicidality were shown in Tables 3 and 4. Table 3 shows crude and adjusted OR $(95 \% \mathrm{CI})$ for suicide attempt in those with low PA or
PMPU, have PA or PMPU, low PA or no PMPU compared with the reference group (have PA or no PMPU). There was a positive additive interaction effects between PA and PMPU on suicide attempt $(p<0.001)$, low PA college student with PMPU were more likely to be with suicide attempt $(\mathrm{OR}=10.26,95 \% \mathrm{CI}$ : 6.65-15.82). After adjusting for confounding factors, the positive additive interaction effects remained significant $(\mathrm{OR}=9.51$, 95\%CI: $6.15-14.73, P<0.001), \quad$ RERI $=4.85(1.20-8.50)$, $\mathrm{AP}=0.51(0.29-0.73), \quad \mathrm{SI}=2.324(1.34-4.04) \quad($ Table 3$)$. However, there was no additive interaction effects between PA and PMPU on suicidal ideation (Table 4).

\section{Discussion}

A school-based survey was conducted to investigate the independent and interaction effects between physical activity (PA) and problematic mobile phone use (PMPU) on suicide attempt and suicidal ideation in Chinese college students. The prevalence of low PA and PMPU were 16.4 and $27.5 \%$, respectively. Participants with low PA and PMPU exhibit more suicidality. The freshman reported a lower rate of suicide attempt and suicidal ideation than sophomore and junior student, which is similar to previous study [26]. Furthermore, our data

Table 3 Interactions of PA, PMPU and suicide attempt in College Students

\begin{tabular}{|c|c|c|c|c|c|c|}
\hline Modal & $\mathrm{PA} \times \mathrm{PMPU}$ & $\beta$ & $\mathrm{OR}(95 \% \mathrm{Cl})$ & RERI & AP & SI \\
\hline \multirow[t]{4}{*}{ Crude } & Moderate and abovexNo & & 1.00 & & & \\
\hline & Low $\times$ No & 1.02 & $2.78(1.66-4.63)^{* *}$ & & & \\
\hline & Moderate and abovexYes & 1.14 & $3.12(2.10-4.65)^{* *}$ & & & \\
\hline & Low $\times$ Yes & 2.33 & $10.26(6.65-15.82)^{* *}$ & $5.36(1.49-9.23)$ & $0.52(0.31-0.74)$ & $2.38(1.39-4.06)$ \\
\hline \multirow[t]{4}{*}{ Adjusted } & Moderate and abovexNo & & 1.00 & & & \\
\hline & Low $\times$ No & 0.99 & $2.68(1.60-4.48)^{* *}$ & & & \\
\hline & Moderate and abovexYes & 1.09 & $2.98(2.00-4.45)^{* *}$ & & & \\
\hline & Low $\times$ Yes & 2.25 & $9.51(6.15-14.73)^{* *}$ & $4.85(1.20-8.50)$ & $0.51(0.29-0.73)$ & $2.32(1.34-4.04)$ \\
\hline
\end{tabular}

Note: ${ }^{*} P<0.05$; ${ }^{*} P<0.001$; OR is odds ratio; $\mathrm{Cl}$ is confidence interval; RERI is relative excess risk of interaction; AP is attributable proportions; $\mathrm{SI}$ is synergy index; PA is Physical activity; PMPU is problematic mobile phone use; Adjusted model controlled gender, grade, only child, parents' educational level; registered residence, self-reported family economic situation 
Table 4 Interactions of PA, PMPU and suicidal ideation in College Students

\begin{tabular}{|c|c|c|c|c|c|c|}
\hline Modal & $\mathrm{PA} \times \mathrm{PMPU}$ & $\beta$ & $\mathrm{OR}(95 \% \mathrm{Cl})$ & RERI & AP & SI \\
\hline \multirow[t]{4}{*}{ Crude } & Moderate and abovexNo & & 1.00 & & & \\
\hline & Low $\times$ No & 0.85 & $2.34(1.64-3.34)^{* *}$ & & & \\
\hline & Moderate and abovexyes & 1.16 & $3.19(2.46-4.14)^{* *}$ & & & \\
\hline & Low $\times$ Yes & 1.36 & $3.90(2.67-5.69)^{* *}$ & $-0.63(-2.53-1.28)$ & $-0.16(-0.68-0.36)$ & $0.82(0.46-1.48)$ \\
\hline \multirow[t]{4}{*}{ Adjusted } & Moderate and abovexNo & & 1.00 & & & \\
\hline & Low XNo & 0.82 & $2.26(1.58-3.24)^{* *}$ & & & \\
\hline & Moderate and abovexYes & 1.13 & $3.09(2.38-4.02)^{* *}$ & & & \\
\hline & Low $\times$ Yes & 1.29 & $3.63(2.48-5.31)^{* *}$ & $-0.73(-2.27-0.81)$ & $-0.20(-0.68-0.27)$ & $0.78(0.46-1.34)$ \\
\hline
\end{tabular}

Note: ${ }^{*} P<0.05$; ${ }^{* *} P<0.001$; OR is odds ratio; $\mathrm{Cl}$ is confidence interval; RERI is relative excess risk of interaction; AP is attributable proportions; $\mathrm{SI}$ is synergy index; PA is Physical activity; PMPU is problematic mobile phone use; Adjusted model controlled gender, grade, only child, parents' educational level; registered residence, self-reported family economic situation

reveals that PA and PMPU have main effects on suicidality independently, as well as interaction effects between PA and PMPU on suicide attempt but not suicidal ideation.

We observed low PA in $16.4 \%$ of participants, which was similar to Brazilian adolescents (16.2\%) [27]. Previous research has found an inversely relationship between PA with suicide attempt and suicidal ideation [6]. An investigation in National Youth Risk Behavior Survey in the United States suggested that increased exercise frequency was less at risk of suicide attempt and suicidal ideation [28]. However, another study in the United States showed that $13.8 \%$ of adolescents had never participated physical activity, which was lower than our study [29], and the study showed that PA was not associated with suicidality, which contradicted our study. There might be our sample was different with others. Furthermore, different evaluation criterion of PA might be influence the results of the study. The heavy learning task is a tradition in China. There are fewer physical education classes in schools when students enter the college stage, it may contribute to reduce time spent in physical activity [30].

As we know, several studies showed the existence of the relationship between PA and suicidality. A study found the level of physical activity was associated with suicide attempt among 74,186 South Korean adolescents, and the result showed gender differences [19]. In our study, there was no significance gender differences for low PA students showed higher rates of suicidality. Advanced studies are needed to confirm whether there are gender differences in the relationship between PA and suicidality.

We investigated PMPU in $27.5 \%$ of participants, which was the same as Coskun's investigation (27.5\%) [31]. Another study reported the ratio of PMPU was $21.3 \%$ in Chinese undergraduates [26], which was lower than us. This may be because the evaluation criterion for PMPU differed. PMPU was found to have an independent effect on suicide attempt and suicidal ideation in this study. Some findings have also reported that adolescents with
PMPU have higher risk of suicide attempt and suicidal ideation, which is consistent with our results [21, 32]. PMPU becomes a very common health problem now [33]. Crumley et al. has found substance abuse is a risk factor for suicide attempt and suicidal ideation [34]. Roggeveen et al. has pointed out that mobile phones use may affect nervous system $[35,36]$. Thus, reduce PMPU may play a significant role in the prevention of suicidality.

Plenty of studies have illuminated significant independent effects between PA and PMPU on suicide attempt and suicidal ideation. Yet study on the interaction effects of PA and PMPU on suicide attempt and suicidal ideation is lacking. Mobile phones have brought great convenience to our life, but also a series of negative influences such as exacerbating sedentary behavior [37]. A study of parentadolescent dyads in the Minnesota found the media equipment in home environment was associated with physical activity [38]. Another study has also shown that mobile phone use is associated with low physical activity [39]. Syvaoja et al. found that PA may benefit attentional processes but mobile phone users may have adverse effect on cognitive functions [40]. Xiao Y [41] et al. reveals that the lowest frequency of physical activity participation and high electronic media use are more likely to have suicide plan. Our study demonstrates the positive additive interaction effect between low physical activity and problematic mobile phone use on suicide attempt.

\section{Conclusions}

In our study, PA and PMPU are cross-sectional associated with suicide attempt and suicidal ideation, with interactions of PA and PMPU on suicide attempt but not suicidal ideation. Suicide prevention efforts that examine both PA and PMPU are vital for early detection of suicide attempt and suicidal ideation among college student.

Abbreviations

PA: Physical activity; LPA: Low physical activity; MPA: Moderate physical activity; PMPU: Problematic mobile phone use; OR: Odds ratio; $\mathrm{Cl}$ : Confidence interval; QR: Quick response; EE: Energy expenditure; 
METs: Metabolicequivalent; IPAQ-SF: International physical activity questionnaire short version; SQAPMPU: Self-rating questionnaire for adolescent problematic mobile phone use; RERI: Relative excess risk of interaction; AP: Attributable proportions; SI: Synergy index

\section{Acknowledgments}

We highly appreciated all project teams, school action teams, and staff and students on the scene.

\section{Authors' contributions}

Conceptualization, Formal analysis, Y.X.(Yang Xie); Writing-original draft, Y.X., and M.Z.(Ming Zhu). Data curation, S.T.(Shuman Tao); Investigation, M.Z., X.W.(Xiaoyan Wu), Y.Y.(Yajuan Yang), L.Z.(Liwei Zou), H.X.(Honglv Xu) Methodology, T.L.(Tingting Li); Supervision, X.W., F.T.(Fangbiao Tao); funding acquisition, Writing-review and editing, Y.W. All the authors who contributed to the manuscript gave their approval for its submission to BMC psychiatry. The work presented here has not been published previously and is not being considered for publication elsewhere. The author(s) read and approved the final manuscript.

\section{Funding}

This study was supported by the National Natural Science Foundation of China (Grant number: 81773455, 81803257) and the Grants for Scientific Research of BSKY from Anhui Medical University (Grant number: XJ201824). These institutions had no further role in the study design, the collection and analysis of data, the writing of the report, and the decision to submit the paper for publication.

\section{Availability of data and materials}

The datasets that were generated analyzed for the current study are not publicly available as the author does not have permission to share the data.

\section{Ethics approval and consent to participate}

The design and data collection were reviewed and approved by the Ethics Committee of Anhui Medical University, China. All participants wrote informed consent for inclusion prior to the administration of the survey.

\section{Consent for publication}

Not Applicable.

\section{Competing interests}

The authors declare no conflict of interest.

\section{Author details}

'Department of Maternal, Child and Adolescent Health, School of Public Health, Anhui Medical University, No 81 Meishan Road, Hefei 230032, Anhui, China. ${ }^{2}$ Zhongshan School of Medicine, Sun Yat-Sen University, 74 2nd Zhongshan Road, Yuexiu District, Guangzhou 510000, Guangdong, China. ${ }^{3}$ MOE Key Laboratory of Population Health Across Life Cycle, No 81 Meishan Road, Hefei 230032, Anhui, China. ${ }^{4}$ Anhui Provincial Key Laboratory of Population Health and Aristogenics, Anhui Medical University, No 81 Meishan Road, Hefei 230032, Anhui, China. ${ }^{5} \mathrm{NHC}$ Key Laboratory of Study on Abnormal Gametes and Reproductive Tract, No 81 Meishan Road, Hefei 230032, Anhui, China. ${ }^{6}$ Department of Nephrology, The Second Hospital of Anhui Medical University, 678 Furong Road, Hefei 230601, Anhui, China. ${ }^{7}$ School of Nursing, Anhui Medical University, 15 Feicui Road, Hefei 230601, Anhui, China.

Received: 22 May 2020 Accepted: 15 October 2020

Published online: 23 October 2020

\section{References}

1. Beiter R, Nash R, McCrady M, Rhoades D, Linscomb M, Clarahan M, Sammut S. The prevalence and correlates of depression, anxiety, and stress in a sample of college students. J Affect Disord. 2015;173:90-6.

2. Hawton K, Saunders KEA, O'Connor RC. Self-harm and suicide in adolescents. Lancet. 2012;379:2373-82.

3. Eisenberg D, Hunt J, Speer N. Mental health in American colleges and universities: variation across student subgroups and across. J Nerv Ment Dis. 2013;201(1):60-7.

4. Mortier P, Cuijpers P, Kiekens G, Auerbach RP, Demyttenaere K, Green JG, Kessler RC, Nock MK, Bruffaerts R. The prevalence of suicidal thoughts and behaviours among college students: a meta-analysis. Psychol Med. 2018; 48(4):554-65.

5. Robins A, Fiske A. Explaining the relation between religiousness and reduced suicidal behavior: social support rather than specific beliefs. Suicide Life Threat Behav. 2009;39(4):386-95.

6. Vancampfort D, Hallgren M, Firth J, Rosenbaum S, Schuch FB, Mugisha J, Probst M, Van Damme T, Carvalho AF, Stubbs B. Physical activity and suicidal ideation: a systematic review and meta-analysis. J Affect Disord. 2018;225:438-48.

7. Chou CH, Ko HC, Wu JY, Cheng CP. The prevalence of and psychosocial risks for suicide attempts in male and female college students in Taiwan. Suicide Life Threat Behav. 2013;43(2):185-97.

8. Lee S, Dwyer J, Paul E, Clarke D, Treleaven S, Roseby R. Differences by age and sex in adolescent suicide. Aust N Z J Public Health. 2019;43(3):248-53.

9. Liu CH, Stevens C, Wong S, Yasui M, Chen JA. The prevalence and predictors of mental health diagnoses and suicide among U.S. college students: implications for addressing disparities in service use. Depress Anxiety. 2019;36(1):8-17.

10. Li ZZ, Li YM, Lei XY, Zhang D, Liu L, Tang SY, Chen L. Prevalence of suicidal ideation in Chinese college students: a meta-analysis. PLoS One. 2014;9(10): e104368.

11. Wang W, Ai M, Kuang L, Chen JM, Gan Y, Zeng Y, Lou DD, Liu WT, Niu YJ, Phillips MR. Prevalence of social distance and restriction among college students with suicide attempts in Chongqing. Chin J Epidemiol. 2011;32(4): 341-5.

12. Mortier P, Auerbach RP, Alonso J, Axinn WG, Cuijpers P, Ebert DD, Green JG, Hwang I, Kessler RC, Liu H, Nock MK, Pinder-Amaker S, Sampson NA, Zaslavsky AM, Abdulmalik J, Aguilar-Gaxiola S, Al-Hamzawi A, Benjet C, Demyttenaere K, Florescu S, De Girolamo G, Gureje O, Haro JM, Hu C, Huang Y, De Jonge P, Karam EG, Kiejna A, Kovess-Masfety V, Lee S, Mcgrath JJ, O'neill S, Nakov V, Pennell BE, Piazza M, Posada-Villa J, Rapsey C, Viana MC, Xavier M, Bruffaerts R. Suicidal thoughts and behaviors among college students and same-aged peers: results from the World Health Organization World Mental Health Surveys. Soc Psychiatry Psychiatr Epidemiol. 2018;53(3): 279-88.

13. McMahon EM, Corcoran P, O'Regan G, Keeley H, Cannon M, Carli V, Wasserman C, Hadlaczky G, Sarchiapone M, Apter A, Balazs J, Balint M, Bobes J, Brunner R, Cozman D, Haring C, losue M, Kaess M, Kahn JP, Nemes B, Podlogar T, Poštuvan V, Sáiz P, Sisask M, Tubiana A, Värnik P, Hoven CW, Wasserman D. Physical activity in European adolescents and associations with anxiety, depression and well-being. Eur Child Adolesc Psychiatry. 2017; 26(1):111-22.

14. Choudhury S, Saha I, Som TK, Ghose G, Patra M, Paul B. Mobile phone involvement and dependence among undergraduate medical students in a medical College of West Bengal. India J Educ Health Promot. 2019;8:1.

15. Martinotti G, Villella C, Di Thiene D, Di Nicola M, Bria P, Conte G, Cassano M, Petruccelli F, Corvasce N, Janiri L, Giuseppe LT. Problematic mobile phone use in adolescence: a cross-sectional study. J Public Health. 2011;19(6):545-51.

16. Lee H, Kim MS, Son HK, Ahn S, Kim JS, Kim YH. Discriminating power of socio-demographic and psychological variables on addictive use of cellular phones among middle school students. J Korean Acad Nurs. 2007:37(6): 957-65.

17. Sanchez-Martinez M, Otero A. Factors associated with cell phone use in adolescents in the community of Madrid (Spain). CyberPsychol Behav. 2009; 12(2):131-7.

18. Halayem S, Nouira O, Bourgou S, Halayem S, Nouira O, Bourgou S, Bouden A, Othman S, Halayem M. The mobile: a new addiction upon adolescents. Tunis Med. 2010;88(8):593-6.

19. Xie H, Tao S, Zhang Y, Tao F, Wu X. Impact of problematic mobile phone use and insufficient physical activity on depression symptoms: a collegebased follow-up study. BMC Public Health. 2019;19(1):1640.

20. Gutierrez PM, Davidson CL, Friese AH, Forster JE. Physical activity, suicide risk factors, and suicidal ideation in a veteran sample. Suicide Life Threat Behav. 2016;46(3):284-92

21. Wang $P$, Liu T, Ko C, Lin H, Huang M, Yeh Y, Yen C. Association between problematic cellular phone use and suicide: the moderating effect of family function and depression. Compr Psychiatry. 2014;55(2):342-8.

22. Puciato D, Borysiuk Z, Rozpara M. Quality of life and physical activity in an older working-age population. Clin Interv Aging. 2017;12:1627-34.

23. Nolan RC, Raynor AJ, Berry NM, May EJ. Self-reported physical activity using the international physical activity questionnaire (IPAQ) in Australian adults 
with type 2 diabetes, with and without peripheral neuropathy. Can J Diabetes. 2016;40(6):576-9.

24. Tao S, FJ, WH. The development of self-rating questionnaire for adolescent problematic mobile phone use and the psychometric evaluation in undergraduates. Chin J Sch Health. 2013;1(34):26-9.

25. Wolkenstein P. Centers for disease control and prevention (CDC). Ann Dermatol Venereol. 2000;127(1):131

26. Long J, Liu TQ, Liao YH, Qi C, He HY, Chen SB, Billieux J. Prevalence and correlates of problematic smartphone use in a large random sample of Chinese undergraduates. BMC Psychiatry. 2016;16(1):408.

27. Cheng LA, Mendonça G, Farias Júnior JC. Physical activity in adolescents: analysis of the social influence of parents and friends. J Pediatr. 2014;90(1): 35-41.

28. Sibold J, Edwards E, Murray-Close D, Hudziak JJ. Physical activity, sadness, and suicidality in bullied US adolescents. J Am Acad Child Adolesc Psychiatry. 2015;54(10):808-15.

29. He J, Paksarian D, Merikangas KR. Physical activity and mental disorder among adolescents in the United States. J Adolesc Health. 2018;63(5):628-35.

30. Ma S, Wang B. Correlation between personality characteristics and physical activity of students in a vocational college. Chin I School Health. 2008; 29(12):1149-50.

31. Coskun S, Karayagiz MG. Investigation of problematic mobile phones use and fear of missing out (FOMO) level in adolescents. Community Ment Health J. 2019;55(6):1004-14.

32. Yang YS, Yen JY, Ko CH, Cheng CP, Yen CF. The association between problematic cellular phone use and risky behaviors and low self-esteem among Taiwanese adolescents. BMC Public Health. 2010;10:217.

33. Polo DRM, Mendo LS, Leon DBB, Felipe CE. Mobile abuse in university students and profiles of victimization and aggression. Adicciones. 2017; 29(4):245-55.

34. Crumley FE. Substance abuse and adolescent suicidal behavior. JAMA. 1990; 263(22):3051-6.

35. D'Costa H, Trueman G, Tang L, Abdel-rahman U, Abdel-rahman W, Ong K, Cosic I. Human brain wave activity during exposure to radiofrequency field emissions from mobile phones. Australas Phys Eng Sci Med. 2003;26(4):162-7.

36. Roggeveen S, van Os J, Viechtbauer W, Lousberg R. EEG changes due to experimentally induced $3 \mathrm{~g}$ mobile phone radiation. PLoS One. 2015;10(6): e129496.

37. Noonan RJ, Christian D, Boddy LM, Saint-Maurice PF, Welk GJ, Hibbing PR, Fairclough SJ. Accelerometer and self-reported measures of sedentary behaviour and associations with adiposity in UK youth. J Sports Sci. 2019; 37(16):1919-25.

38. Sirard JR, Laska MN, Patnode CD, Farbakhsh K, Lytle LA. Adolescent physical activity and screen time: associations with the physical home environment. Int J Behav Nutr Phys Act. 2010;7:82.

39. Augner $\mathrm{C}$, Hacker GW. Associations between problematic mobile phone use and psychological parameters in young adults. Int J Public Health. 2012 57(2):437-41.

40. Syvaoja HJ, Tammelin TH, Ahonen T, Kankaanpää A, Kantomaa MT. The associations of objectively measured physical activity and sedentary time with cognitive functions in school-aged children. PLoS One. 2014;9(7): e103559.

41. Xiao Y, Romanelli M, Lindsey MA. A latent class analysis of health lifestyles and suicidal behaviors among US adolescents. J Affect Disord. 2019;255: $116-26$.

\section{Publisher's Note}

Springer Nature remains neutral with regard to jurisdictional claims in published maps and institutional affiliations.

Ready to submit your research? Choose BMC and benefit from:

- fast, convenient online submission

- thorough peer review by experienced researchers in your field

- rapid publication on acceptance

- support for research data, including large and complex data types

- gold Open Access which fosters wider collaboration and increased citations

- maximum visibility for your research: over $100 \mathrm{M}$ website views per year

At $\mathrm{BMC}$, research is always in progress.

Learn more biomedcentral.com/submissions 